\title{
AOIR
}

Selected Papers of \#AoIR2020:

The $21^{\text {st }}$ Annual Conference of the

Association of Internet Researchers

Virtual Event / 27-31 October 2020

\section{RELIVING MEMORIES (OVER AND OVER AGAIN): GIFS, MOVING PHOTOGRAPHY AND THE SMARTPHONE ALBUM}

\author{
Sara Kopelman \\ The Hebrew University of Jerusalem, Israel \\ Paul Frosh \\ The Hebrew University of Jerusalem, Israel
}

Among the most popular and essential smartphone applications are photo-apps. These applications not only enable the seamless display of both still and moving images in smartphone photography albums but even create new looped images from stills taken by the user. This shift potentially changes the temporal experience of everyday digital media from linear temporality to looped, cyclical time, promoting a present tense made visible not through instantaneous capture (photography) or sequential unfolding (film and video), but continual recurrence.

This theoretical paper uses the advent of the GIF as a key product of smartphone photo albums to re-conceptualize the temporal and mnemonic structures of everyday digital photography.

The relation between visible movement and the perception of time guides this paper's focus on the smartphone photo album. While pre-digital photo albums functioned only as vehicles of image-organization and presentation, contemporary smartphone albums also enable - and even initiate - the creation of seemingly new kinds of domestic photography such as 'moving photographs' or 'animated photographs'. The character of these visual products and the processes of their creation vary across operating systems. The Android Photos application, for instance, notifies users with offers to animate their sequences of photographs almost immediately after they are taken, turning them into GIFs - the digital image file format which plays a segment of movement for a few seconds in an endless loop (Eppink, 2014). In parallel, Apple has

Suggested Citation (APA): Kopelman, S. \& Frosh, P. (2020, October). Reliving Memories (Over and Over Again): GIFs, Moving Photography and the Smartphone Album. Paper presented at AolR 2020: The 21 Annual Conference of the Association of Internet Researchers. Virtual Event: AolR. Retrieved from http://spir.aoir.org. 
made 'Live Photos' the default photography mode of the iPhone camera app: this captures 1.5 seconds of video before and after pressing the button to take a photo, and can be looped through the app to create a GIF.

Both Google's and Apple's systems radically disrupt the conventional assumptions of photography theory regarding photography's relations with time. Pre-digital photography theory postulated a key distinction between a photograph and a movie or video: the photograph is static; the movie is characterized by duration. Whereas the photograph was associated with an absolute past, an instantaneous 'what-has-been' (Barthes, 1981) frozen and detached from its own unfolding, moving images were associated with temporal progression (Bazin, 1960; Deleuze, 1986; Baker, 1996). More recent work, however, has altered photography theory's view of the still's inherent pastness, conceptualizing smartphone photography as 'present' and 'live' for two reasons: first, though perceived as still, the digital photograph is actually a high-speed continuous projection of multiple static images (Rubinstein \& Sluis, 2013); second, photographs are increasingly shared instantaneously across digital networks that connect interlocutors across space in the present, and which are experienced as 'live', rather than (or as well as) across time (Frosh, 2019).

Nevertheless, the smartphone image in such accounts still has no experienced duration. This is where the 'moving photographs' of the smartphone photo album transform photographic representation, shifting it from past immobility to a continuous present. More importantly, it is a present whose continuity is created by endless recurrence. The GIF file eliminates the linearity of past-present-future because of its perpetual looped temporality, constituting a hybrid between photographic still and film or video. The endless loop does not produce a pause in looking at the flow of the present, nor does it 'stab' the viewer through absorption into a specific element, as Barthes claims the photograph does. Conversely, however, while the GIF does show movement, it is usually less smooth than the flow of a video (depending on the number of frames per second) and it also lacks sound. As a result, the repetitive movement of the GIF constructs a generalized impression of an event as an artificial duration without development, rather than the structured narrative of an event as a temporal unfolding. The looped movement eliminates the 'telos' from past events, which gives a kind of mythical (but also mechanical) infinity to photographed memories. It is as though the GIF's looped movement functions as the visible incarnation of 'habit-memory', defined by Bergson (1988) as the functional training of memory for the purpose of automating present actions (such as learning text by heart), and which is not recalled as an image of a particular past event. It also makes culturally visible, in its very form as a perpetually recurring computational image, Chun's (2008) designation of the 'enduring ephemeral' as a central characteristic of computational memory: the GIF's looped temporality continually repeats the past as an automated movement of disappearance and reappearance in the present. Everyday smartphone photo-apps therefore come under the principle of time-based looped movement, potentially promoting a technologized 'desire for endlessness' (Hoelzl \& Marie, 2015) in our visualizations of everyday moments.

The emergence of the GIF in the smartphone album thus invites us to reflect on the nature of memory and temporal experience at the cultural level. Despite radical changes 
in photographic technologies and practices, much everyday contemporary photography is still dedicated to users' biographical milestones, such as birthdays, weddings, births, trips, graduation, etc. (Van Dijck, 2008; Keightley \& Pickering, 2014). However, digital photography's capacity for instant, inexpensive and virtually unlimited replication enables sequences of multiple images to replace the single analog photograph as a sacred object of memory. This multiplicity produces a large number of shots for a single event even when taken from the same angle or shooting location (augmented by the long click function that allows for high-speed photographing). Additionally, our private mobile devices are used for the production, processing, distribution and viewing of images across live digital networks (Cruz \& Meyer, 2012): the smartphone enables a cycle of mutual circulation between the consumption of social media and the uploading of images to social media. Smartphone albums - which organize and display images but also initiate temporally novel photographic formats - are at the heart of these complex intersections between continuities in mnemonic practices and techno-cultural transformations.

\section{References}

Baker, G. (1996). Photography between Narrativity and Stasis: August Sander, Degeneration, and the Decay of the Portrait. October, 76, 73-113.

Barthes, R. (1981). Camera Lucida: Reflections on Photography, trans. Richard H. New York: Hill and Wang.

Bazin, A., \& Gray, H. (1960). The Ontology of the Photographic Image. Film Quarterly, 13(4), 4-9.

Bergson H. (1988). Matter and Memory, trans. Paul N.M. and Palmer W.S. New York: Zone Books.

Chun, W. H. K. (2008). The Enduring Ephemeral, or the Future is a Memory. Critical Inquiry, 35(1), 148-171.

Cruz, E. G. \& E.T. Meyer (2012) Creation and control in the photographic process: iPhones and the emerging fifth moment of photography. Photographies, 5(2): 203-221.

Deleuze, G. (1986). Cinema 1: The Movement-Image, trans. Tomlinson H. and Habberjam B. Minneapolis: University of Minnesota.

Eppink, J. (2014). A Brief History of the GIF (so far). Journal of Visual Culture, 13(3), 298-306.

Frosh, P. (2019) The Poetics of Digital Media. Cambridge: Polity.

Hoelzl, I., \& Marie, R. (2015). Softimage: Towards a New Theory of the Digital Image. Intellect Books. 
Keightley, E., \& Pickering, M. (2014). Technologies of Memory: Practices of Remembering in Analogue and Digital Photography. New Media \& Society, 16(4), 576593.

Rubinstein, D., \& Sluis, K. (2013). The Digital Image in Photographic Culture: Algorithmic Photography and the Crisis of Representation. In The Photographic Image in Digital Culture (pp. 36-54). Routledge.

Van Dijck, J. (2008). Digital Photography: Communication, Identity, Memory. Visual Communication, 7(1): 57-76. 